\title{
Technology for producing wear-resistant bimetal bearing based on cast aluminum
}

\author{
Ruslan Kuznetsov', Evgeniy Ol'khovik ${ }^{2, *}$, Mikhail Radkevich ${ }^{3}$, and Pavel Kuznetsov ${ }^{3}$ \\ ${ }^{1}$ JSC «ZVEZDA», Babushkina, 123, 192012, Saint-Petersburg, Russia \\ ${ }^{2}$ Admiral Makarov State University of Maritime and Inland Shipping, Dvinskaya, 5/7, 198035, Saint- \\ Petersburg, Russia \\ ${ }^{3}$ Peter the Great St.Petersburg Polytechnic University, Polytechnicheskaya Street, 29, 195251, Saint- \\ Petersburg, Russia
}

\begin{abstract}
The paper presents the results of research the new technological process for producing bimetallic materials in the composition of "aluminum cast alloy - sintered iron powder" by the method of joint stamping of liquid metal. The purpose of this research is obtain parts with high wear-resistant properties, special sintered powder materials are used, which have an internal porosity to retain lubricant. However, such materials do not fit well with traditional aluminum alloys. This problem is may be solved by creating new bimetallic alloys, part of which is an outer casing, and the other materials is the functional bearing. To accomplish this task, we conducted a study of a new technology for joint stamping of liquid metal. In order to optimize and increase the reliability of the experiment, the pressing pressure, the pressure holding time, and the tooling temperature of the matrix were taken as quantitative factors. The effect of the applied pressure on the mechanical properties of the base material and the facing layer was determined on a longitudinal section of the obtained samples by the Vickers method. It was revealed that the gradient of increasing hardness is directed to the outer radius of the workpiece, that is, to the opposite crystallization front. The high level of bimetal adhesion is explained by the presence of a uniform moderate zone of mutual solubility, including due to the violation of the porous surface layer of the powder billet.
\end{abstract}

\section{Introduction}

Nowadays, great importance is given to increasing the regulated overhaul life of engines and components in the process of manufacturing engineering or shipbuilding products for civil and other application. One of the ways to solve this task is to increase the reliability of antifriction parts, in particular, sliding bearings [1]. The possibility of various designs, high accuracy, small radial dimensions, the ability to work in water, corrosive environments, as well as under shock and vibration loads make the sliding bearings indispensable in the design of modern components and assemblies [2]. Based on the requirements of economic

\footnotetext{
* Corresponding author: olhovikeo@gumrf.ru
} 
feasibility, regardless of the operating conditions, most modern sliding bearings are a bimetallic compound - a composition of dissimilar metals. The basis of such a pair, as a rule, is used relatively cheap construction materials: babbits, antifriction brass, bronze and a number of aluminum alloys are used as the working wear-resistance layer. Due to the high antifriction properties, which including due to the effect of "self-lubrication" and competitive cost, the use of sintered porous materials based on iron seems promising $[3,4]$. However, the possibility of using them as bearing inserts is significantly limited due to the difficulty of making permanent connections with them. The aim of the work was an experimental study of the possibility of obtaining high-quality bimetallic compounds by joint stamping of a liquid aluminum casting alloy AlSi9Mg and a working liner made of sintered porous iron powder material ( $\mathrm{Fe}-$ base, $\mathrm{C}-0.025 \%, \mathrm{Fe} 2 \mathrm{O} 3<0.2 \%$ ). The application, like a bimetallic pair of sintered powdered iron material and an aluminum casting alloy as a bimetallic pair of a sliding bearing, is of considerable interest. The use of stamped casting alloy as a basis allows expanding the range of bimetallic products and creates prerequisites for improving product quality $[5,6]$. The use of powder metallurgy technology allows to obtain a working layer of a bimetallic product with the highest and special physical, mechanical and operational properties [7]. The preparation of permanent iron-aluminum compounds is known to be difficult due to the differences in their physicochemical properties, melting points, linear expansion coefficients, as well as the high reactivity of aluminum to oxygen (A12O3 ) [8]. In addition, an important criterion for the quality of the adhesive layer is the magnitude, continuity and stoichiometric composition of $\mathrm{Fe}-\mathrm{Al}$ intermetallic formed in the process of diffusion interaction of materials. Industrial methods for producing aluminum-steel billets are solid-phase methods, such as rolling or welding. However, this group of technological processes requires special preparation of materials and initial blanks. It is significantly limited in the geometry of the final product and the range of materials of the cladding layer, in particular, it does not allow fully using the advantages of powder metallurgy and casting technology. Thus, to obtain shaped bimetallic blanks from a given pair of materials, it is necessary to develop a fundamentally new production technology that provides a high level of special properties and adhesion strength of layers of materials.

\section{Materials and method}

To implement this task in this work, the authors conducted studies on the possibility of using the technology of joint stamping of liquid metal (SLM) [9-11] and sintered powder material. Samples for the study were prototypes of bimetal plain bearings with an outer diameter of $61 \mathrm{~mm}$ and height of $14 \mathrm{~mm}$. The material of the working layer is a porous billet of size: $\mathrm{D}=33.1 \mathrm{~mm}, \mathrm{~d}=12.9 \mathrm{~mm}, \mathrm{~h}=14 \mathrm{~mm}$, pre-extruded with a constant density of $85 \pm 0.5 \%$, which is consistent with the recommended intervals for anti-friction parts. Sintering was carried out according to the factory technology in a protective environment of inert gas.

In order to optimize and increase the reliability of the experiment, the pressing pressure $(\mathrm{P})$, holding pressure time $(\mathrm{t})$ and the die tooling temperature $(\mathrm{T})$ were taken as quantitative factors. The choice of parameters and their interval values are explained by the research of the authors $[10,11]$. 


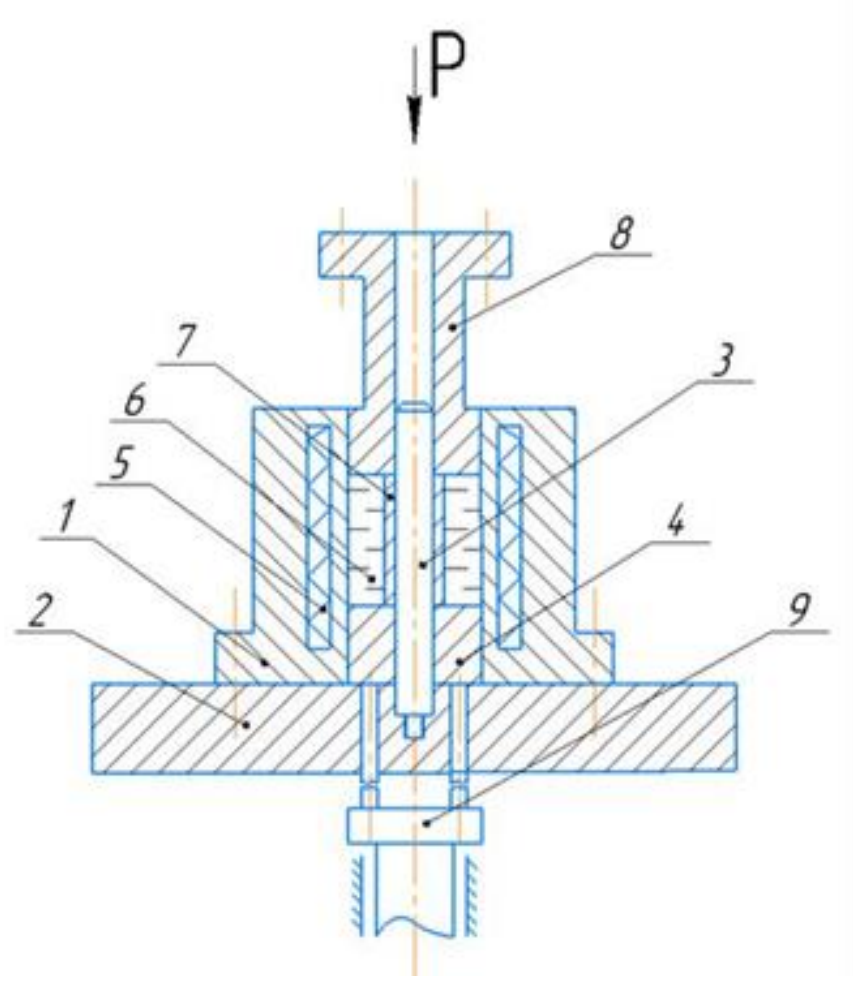

Fig. 1.Schematic diagram of the joint stamping of liquid metal and sintered working insert: $1-$ matrix, 2 - plate, 3 - mandrel, 4 - support, 5 - heating element, 6 - liquid metal, 7 - working insert, 8 - punch, 9 - ejector.

The schematic diagram of SLM equipment is shown on Fig. 1. Stamping of bimetal samples was carried out by piston pressing as follows - fig.1, the matrix 1 was mounted and fixed on the bottom plate 2 ; the mandrel 3 in the support 4 was coaxially mounted in the cavity of the matrix 1 . On the working surface of the matrix, mandrel and supports applied a protective non-stick coating.

The assembled equipment was heated to the operating temperature using a heating element 5. A fixed dose of liquid aluminum of the base 6 was poured into matrix 1 in accordance with the volume of the obtained blank. Working insert 7 of the sintered powder material, fixed on the mandrel 3 using the punch 8 , was immersed in the liquid metal of the base 6 and fixed in the desired position. Upon further movement of the punch 8 , joint stamping of the liquid metal 6 and insert 7 was performed. At the same time, the pressure was held until the base was completely crystallized and the liquid metal penetrated into the open pores of the powder material of the insert 7 . The finished bimetallic product was pushed out of the matrix 1 by the ejector 9 .

\section{Results}

The effect of applied pressure on the mechanical properties of the base material and the cladding layer was determined on a longitudinal section of the obtained samples by the Vickers method. The performed measurements show a static change in the hardness of the casting alloy in the range from 47.0 to 77.5 units with increasing pressure on the melt in the crystallization process from 0 to $215 \mathrm{MPa}$. This is characterized by the fact that the gradient 
of increasing hardness is directed toward the outer radius of the blank, i.e. towards the opposite crystallization front, which is analogous to the chill casting and indicates the segregation of metal. However, if in the case of the casting technology, this spread does not usually exceed $5 \%$, then in the SLM process the hardness parameters across the cross section could differ by $10 \%$ or more, which can be explained by the accelerated heat transfer at the "liquid metal -forming tool" border. This was confirmed when measuring the hardness of a casting alloy over the blank height in its perpendicular section. It was possible to increase the homogeneity of the cast material by increasing the temperature of the die tooling temperature to a temperature exceeding the temperature of the alloy casting by $50 \div 100^{\circ} \mathrm{C}$.

Analysis of the change in the hardness of the sintered powder billet depending on the applied pressure did not reveal significant changes in the range of $0 \div 100 \mathrm{MPa}$, with the only feature that the density of the material slightly increased in the area of contact with the base material. The excess of hardness in this zone reaches $10 \%$ but is not critical due to the lack of influence on the performance properties of the wear-resistance layer.

The adhesive strength of the samples was determined by the standard cut method described in ISO 5187. Measurements were carried out on the «LosenHausen» hydraulic test facility with a nominal force of $16000 \mathrm{~kg}$. Optimal process parameters: $\mathrm{P}=80 \div 100$ $\mathrm{MPa}, \mathrm{T}=700 \div 800^{\circ} \mathrm{C}$ and $\mathrm{t}=15 \div 20 \mathrm{~s}$ the adhesion strength reaches $\tau \mathrm{c}=48 \ldots 50 \mathrm{MPa}$, which is 2.5 times higher than the similar values obtained by the method of casting cladding for a given pair of materials.

It became possible to compare the revealed patterns due to the research of the microstructure of the contact layer of the obtained samples. So, on samples obtained by casting with pre-cladding (Fig. 2a) and having the lowest strength properties, the boundary of the intermetallic layer composition is clearly expressed, the basis of which, from the process conditions, is FeAl3 and Fe2A15. The presence of a brittle intermetallic layer with low plastic properties $(\sigma b=15 \div 17 \mathrm{MPa})$ explains the low strength properties of the obtained compound.

An increase in pressure applied to the liquid melt above $215 \mathrm{MPa}$ leads to an adsorption decrease in the surface strength of the sintered powder billet and the introduction of an aluminum melt into a solid (Fig. 2b), which is a manifestation of the Rehbinder effect. However, it was not possible to compare the data of such an effect on the strength properties of the compound of materials due to the significant deformation of the powder material, which was unacceptable for the implemented technology.

Figure $2 \mathrm{c}$ shows the boundary of the contact layer of the blank obtained in the stamping modes. The relatively high level of strength properties, in this case, is confirmed by the presence of a uniform moderate zone of mutual solubility, including due to the violation of the porous surface layer of the powder billet. At the same time, the overall geometrical accuracy of the sleeve of the sintered material is not disturbed under these process conditions. 
a)

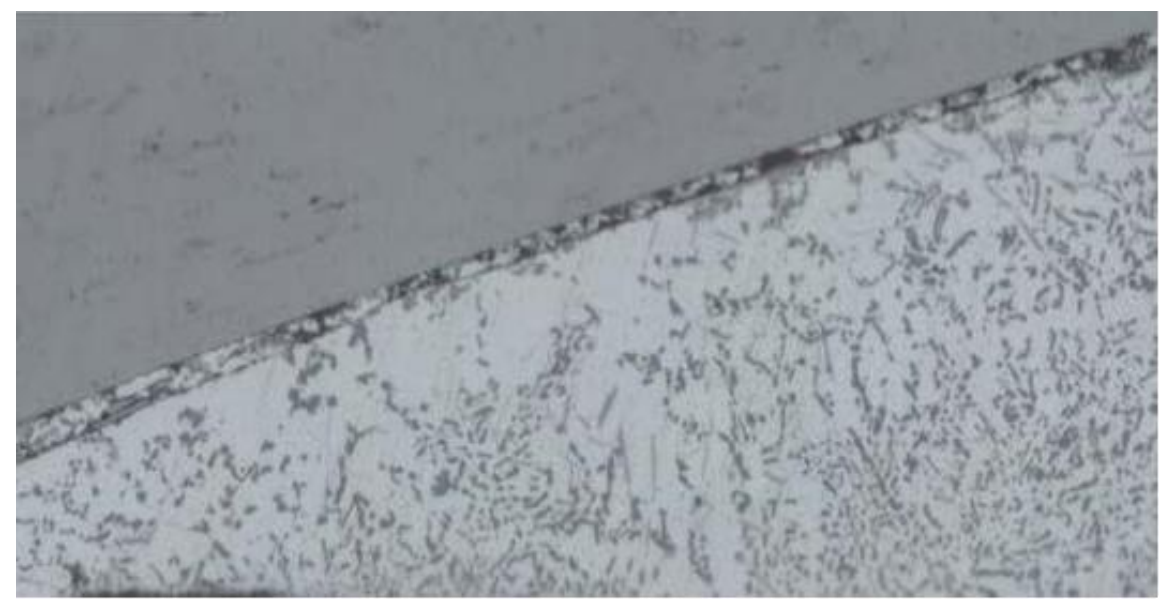

b)

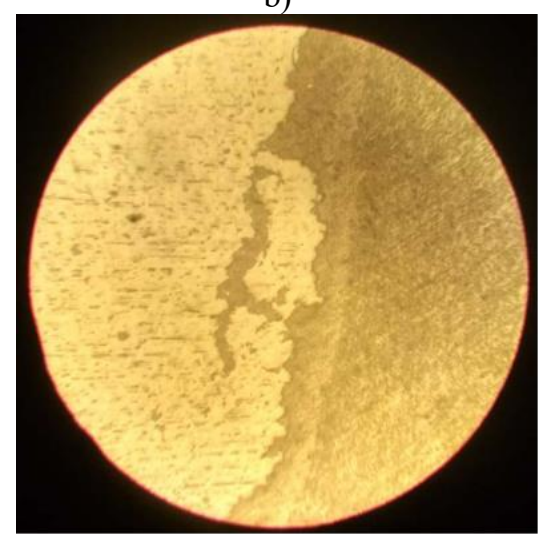

c)

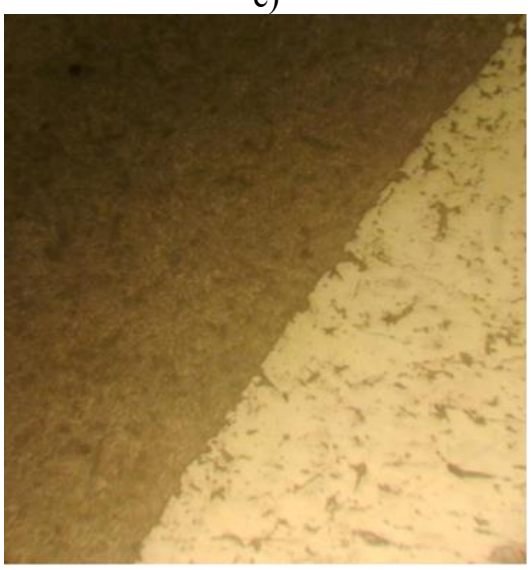

Fig. 2. The microstructure of the contact layer of the bimetallic samples «AlSi9Mg+ iron powder»: a - With a pronounced zone of the intermetallic layer (zoom x500); $b$ - With a zone of mutual penetration with penetration of powder material (zoom x250); $\mathrm{c}$ - With satisfactory mutual solubility area (zoom x500). 


\section{Discussion}

The main advantage of the developed technology is that it has become possible to use commercial aluminum alloys and iron powder materials to produce bimetallic castings. Additionally, the problem of obtaining a dense structure of cast bimetal and the lack of porosity of the metal is solved, a short one significantly affects the mechanical properties [12] of the part structure and its tightness.

Tools for producing bimetallic castings are also expanding due to new SLM technology, it can be chill tooling or special methods, for example, based on the manufacture of tooling using additive technology [13] or another.

\section{Conclusions}

The proposed technology of joint stamping of liquid metal and sintered powder material makes it possible to obtain bimetallic compounds that are superior in adhesion to similar compounds from compact materials obtained by rolling methods. The method practically does not limit the range of used materials and allows significantly expanding the range of produced blanks, significantly reducing the complexity due to the lack of long-cycle preparatory operations and the use of universal stamping equipment.

From the point of view of improving this technology, the promising direction is the determination of the effect of wettability of the powder material with liquid melt on the adhesive strength of the bimetallic compound, definition of the necessity of introducing a damping layer that affects the composition of the intermetallic phase, for example - zinc or aluminum.

\section{References}

1. W. Litwin, A. Olszewski, Tribology Transactions, 57(1), 114-122 (2013) doi:10.1080/10402004.2013.856980

2. R. Naresh, A. Aman, A. Gupta, S. Sivarajan, Advances in Materials and Metallurgy, 18 (2018) doi:10.1007/978-981-13-1780-4_1

3. I.M. Fedorchenko, V. D. Zozulya, I. A. Panfilova, Journal of Friction and Wear, 2, No. 6, 965-971 (1981) https://www.scopus.com/record/display.uri?eid=2-s2.00019633193\&origin $=$ resultslist\&sort $=$ plf-

$\mathrm{f} \& \mathrm{src}=\mathrm{s} \& \mathrm{sid}=14 \mathrm{dc} 0 \mathrm{~d} 2549251 \mathrm{fc} 3 \mathrm{~b} 5 \mathrm{~d} 0 \mathrm{cc} 512 \mathrm{c} 2 \mathrm{f} 7 \mathrm{db} 4 \& \mathrm{sot}=$ autdocs\&sdt=autdocs $\& \mathrm{sl}=1$ $7 \&$ s=AU-ID\%287006684844\%29\&relpos=57\&citeCnt=0\&search Term

4. Y.A. Vallikivi, V.V. Pushkarev, Soviet Powder Metallurgy and Metal Ceramics, 13(10), 862-864 (1974) doi:10.1007/bf01177941.

5. K. Czelej, K.J. Kurzydłowski, Scripta Materialia, 177, 162-165 (2020) doi: 10.1016/j.scriptamat.2019.10.030

6. Z. Xu, X. Liu, R. Chen, D. Shan, IOP Conference Series: Materials Science and Engineering, 612, 032024 (2019) doi:10.1088/1757-899x/612/3/032024

7. K. Nová, F. Průša, P. Novák, Chemicke Listy, 113, No. 7, 422-428 (2019) https://www.scopus.com/record/display.uri?eid=2-s2.0-

85071270118 \&origin $=$ resultslist\&sort $=$ plf-

$\mathrm{f} \& \mathrm{src}=\mathrm{s} \& \mathrm{sid}=76582646218530 \mathrm{fb} 1406 \mathrm{f} 973 \mathrm{~b} 66293 \mathrm{f} 3 \& \mathrm{sot}=$ autdocs\&sdt=autdocs\&sl=1

8\&s=AU-ID\%2826645037700\%29\&relpos=2\&citeCnt=0\&searchTerm

8. K. Sato, N. Sekido, K. Yoshimi, Journal of the Japan Society of Powder and Powder Metallurgy, 66(10), 478-484 (2019) doi:10.2497/jjspm.66.478 
9. R.V. Kuznetsov, E.O. Olhovik, Vestnik of Admiral Makarov State University of Maritime and Inland Shipping, 11(5), 902-909 doi:10.21821/2309-5180-2019-11-5902-909

10. R.V. Kuznetsov, M. M. Radkevich, P. A. Kuznetsov, RU 2696164 C1, IPC B22D 18/02, B32B 15/00. Russian Federation, assignee (2019)

11. R. Kuznetsov, M. Radkevich, Science \& Education, 5, 1142-1149 (2016) DOI: 10.1872/MMF-2016-105

12. E. Ol'khovik, IOP Conference Series: Materials Science and Engineering, 91, 012022 (2015) doi:10.1088/1757-899x/91/1/012022

13. E. Olkhovik, A.A. Butsanets, A.A. Ageeva, IOP Conference Series: Materials Science and Engineering, 140, 012013 (2016) doi:10.1088/1757-899x/140/1/012013. 